\title{
Small intestinal intraepithelial lymphocyte levels in cow's milk protein intolerance
}

\author{
A. D. Phillips, S. J. RICE, N. E. FRANCE, AND J. A. WALKER-SMith \\ From the Queen Elizabeth Hospital for Children, Hackney Road, London
}

SUMMARY The mean small intestinal intraepithelial lymphocyte count in seven children with untreated cow's milk protein intolerance (CMPI) on a milk-containing diet was significantly higher than 22 control children also having a milk-containing diet. Ten milk-intolerant children on a milkfree diet had a mean intraepithelial lymphocyte count which was significantly lower than the level in the 22 control children on a milk-containing diet. When these 10 children were challenged with cow's milk they relapsed clinically, and in every case the intraepithelial lymphocyte count rose, although it remained within normal limits. Nineteen children on milk-free diets who had recovered from CMPI had a mean lymphocyte count which was also significantly lower than controls on normal diets, suggesting that when milk is removed from the diet the lymphocyte count is low regardless of whether the child is milk sensitive or not. The reaction of intraepithelial lymphocytes to milk in CMPI is markedly different from their response to gluten in coeliac disease.

The suggestion that variation in the number of lymphocytes within the surface epithelium of the small intestine could be important in the assessment of mucosal abnormality was first put forward by Ferguson and Murray (1971). Since then their level has been shown to be greatly increased in the small intestinal mucosa of children with coeliac disease, both when the disease is untreated and after relapse following a gluten challenge (Lancaster-Smith et al., 1976; Mavromichalis et al., 1976). Levels return to normal when the child is on a gluten free diet (Mavromichalis et al., 1976). These observations are of practical value in the distinction between coeliac and non-coeliac enteropathies in childhood (de Peyer et al., 1978). The aims of this study were to establish the pattern of the intraepithelial lymphocyte response to cow's milk in cow's milk protein intolerance, to compare levels found with those reported in coeliac disease, and to evaluate the usefulness of intraepithelial lymphocyte levels in routine diagnostic pathology.

\section{Methods}

PATIENTS

The patients were divided into three groups based on their clinical details and their diet at the time of biopsy.

Received for publication 26 January 1979

\section{Control children}

These were 22 children on a normal, milk-containing diet, with a histologically normal mucosa, minimal clinical symptoms (no diarrhoea) at the time of biopsy, and who were symptom-free subsequently.

\section{Children with history of CMPI from which they had recovered}

These were 19 children on a milk-free diet and with a histologically normal mucosa at the time of biopsy, who were successfully regraded onto a cow's milkcontaining diet immediately after the biopsy. They had been placed on a cow's milk-free diet because of previous clinical evidence of intolerance to cow's milk protein-that is, they had presumably recovered from CMPI. No post-challenge biopsy was performed.

\section{Children with CMPI}

This group was subdivided into (i) seven children with untreated CMPI on a normal milk-containing diet, and (ii) 10 children who underwent pre- and post-milk challenge biopsies, suffering clinical relapses on the administration of a milk-containing diet.

The diagnosis of CMPI was based on the child's clinical improvement after the removal of cow's milk from the diet, the demonstration of a normal or near-normal small intestinal mucosa on a cow's milk-free diet, and the child's clinical and histo- 
logical relapse on the return of cow's milk into the diet. A lactose tolerance test was performed before the milk challenge to exclude the diagnosis of lactose intolerance (Walker-Smith et al., 1978).

Fluoroscopically monitored small intestinal biopsies were taken using a double port modification of the Crosby paediatric capsule (Kilby, 1976) which provides two samples. One sample was frozen for immediate histological examination using cryostat sections; subsequently it was placed in formal-saline and processed routinely. The other sample was fixed at once in formal-saline. Intraepithelial lymphocyte levels were determined using haematoxylin and eosin stained $5 \mu \mathrm{m}$ thick sections of the latter, formal-saline fixed specimen. The lymphocytes were counted in the epithelium covering the entire villus and the results were expressed as the number of lymphocytes per 100 epithelial cells, a minimum of 500 epithelial cells being counted (Ferguson et al., 1976). Student's $t$ test, modified for small samples, was applied to the results.

To determine the variation in the number of intraepithelial lymphocytes in adjacent areas of the mucosa the intraepithelial lymphocytes were counted in both samples from 10 biopsies selected at random from the groups under study. The difference between the samples was expressed as a percentage of the smaller count.

\section{Results}

The mean difference in intraepithelial lymphocyte counts between adjacent areas of mucosa taken in a biopsy was $12 \cdot 1 \%$ (standard deviation $=9 \cdot 1)$.

\section{GROUP 1}

The mean level of intraepithelial lymphocytes per 100 epithelial cells (IEL) for the 22 control patients on normal diets was 23.4 , with a normal range of $11 \cdot 8-35 \cdot 0$, basing the range on the mean \pm two standard deviations (Fig. 1). To examine the effect of age on IEL, this control group was divided into those under 2 years of age (12 children, mean age 16 months) and those over 2 years ( 10 children, mean age 58 months). No significant difference was found between the IELs of these age groups.

\section{GROUP 2}

The mean IEL of the second group of 19 children on milk-free diets was $17 \cdot 1$, with a standard deviation of $4 \cdot 2$. This is statistically significantly lower than the mean IEL for control children on normal diets $(P<0.005)$, as shown in Fig. 2.

GROUP 3 (i)

The seven children on normal diets who were sub-

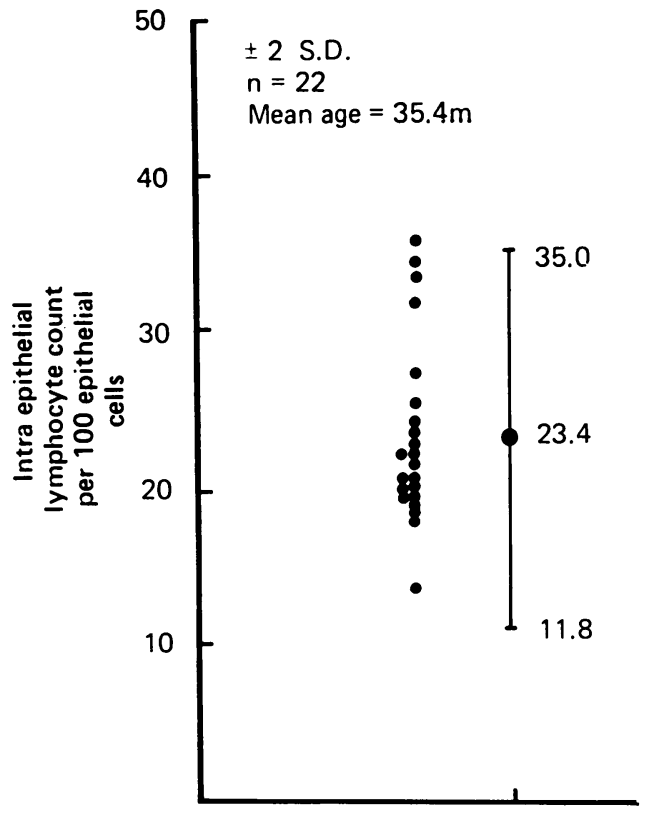

Fig. 1 Intraepithelial lymphocyte counts in control children with normal mucosa on a normal diet (group 1).

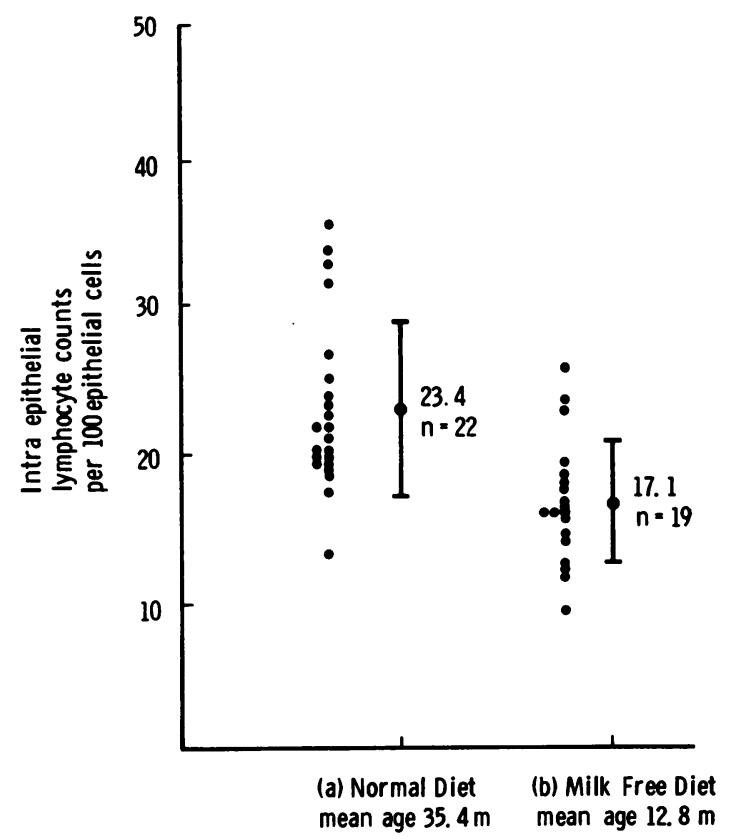

Fig. 2 Intraepithelial lymphocyte counts in (a) control children on a normal diet (group 1) vs. (b) children on a cow's milk-free diet (group 2). $P<0.005$. 
sequently diagnosed as fbeing cow's milk protein intolerant, had a mean IEL of 38.5 , with a standard deviation of 14.0 (Fig. 3). This is significantly higher $(P<0.005)$ than the control group on a normal diet

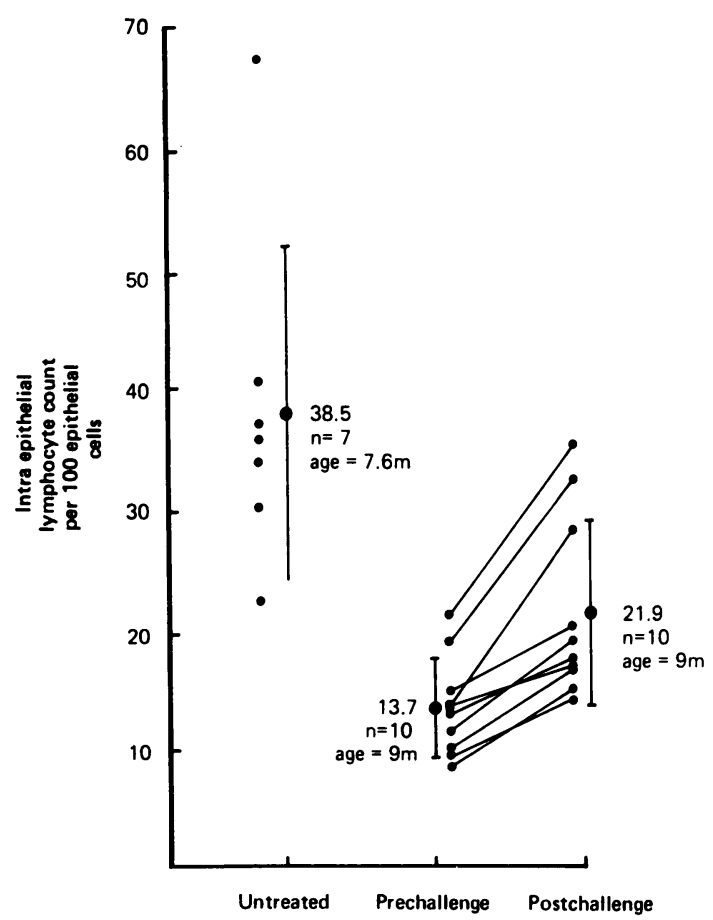

Fig. 3 Intraepithelial lymphocyte counts in children with cow's milk protein intolerance (group 3).

GROUP 3 (ii)

The IEL results for the 10 children who clinically relapsed on milk challenge are shown in Fig. 3. The pre-milk challenge IEL was 13.7 (standard deviation $4 \cdot 2$ ), the post-challenge IEL was 21.9 (standard deviation 7.7). The mean individual difference between the pre- and post-milk challenge biopsies was $59.7 \%$ (standard deviation $=25.9$ ). The pre-milk challenge IEL is significantly lower than the postmilk challenge IEL $(P=0.005)$. It is also significantly lower than the IELs of group 3 (i) (untreated CMPI, $P<0.005$ ), group 1 (control patients on normal diets, $P<0.005$ ), and group 2 (patients on milk-free diets, $P=0.025$ ). The post-milk challenge IEL was not significantly different from group 1 (control patients on normal diets), but was significantly lower than group 3 (i) (untreated CMPI, $P<0.005$ ).

\section{Discussion}

The range of intraepithelial lymphocytes per 100 epithelial cells for the control children on normal diets $(11 \cdot 8-35 \cdot 0)$ falls within previously published ranges for children (Ferguson et al., 1976; McNicholl et al., 1976) and is also similar to the range reported by Ferguson and Murray (1971) for 40 adults with no gastrointestinal disease. From these data and from our finding of no significant difference between the IELs of control children under 2 years of age and over 2 years we have concluded that normally there is no change in the levels of intraepithelial lymphocytes with age from early childhood to adulthood.

Group 2 children on milk-free diets had had previous clinical evidence of cow's milk protein intolerance. However, as they were successfully regraded onto cow's milk after their pre-milk challenge biopsies, it was concluded that they were not cow's milk protein intolerant at that time. None of the children has suffered relapses since then. It is interesting therefore that the IEL for this group is significantly lower than the control group on a normal diet and suggests that the removal of cow's milk from their diets has resulted in a lowering of the level of intraepithelial lymphocytes, although still within the normal range. A similar situation existed for the children with cow's milk protein intolerance placed on milk-free diets, although the IEL was even lower. Thus, this phenomenon appears to be independent of whether the child is cow's milk protein intolerant or not, although it may be more marked in children sensitive to cow's milk.

In the children with untreated cow's milk protein intolerance, although the levels of intraepithelial lymphocytes were higher than the upper limit of normal in six of the seven cases, only one count approached the levels usually found in untreated coeliac disease and this may allow some differentiation between the two diseases. Also when cow's milk protein intolerant children placed on cow's milk-free diets were challenged with cow's milk and clinically relapsed, all intraepithelial lymphocyte levels rose but stayed within normal limits. The rise in intraepithelial lymphocyte levels was much greater than the variation found between adjacent areas of mucosa. It would appear therefore that the response of intraepithelial lymphocytes to cow's milk in cow's milk protein intolerance is different to the response of intraepithelial lymphocytes to gluten in coeliac disease. A shorter period of challenge is used in cow's milk protein intolerance, usually four to five days, which may explain why the rise in intraepithelial lymphocytes remains within the normal limits. However, Ferguson (1974) has shown that in 
adult coeliac disease an abnormal level of intraepithelial lymphocytes can occur within 12 to 24 hours of gluten challenge and thus it is more likely that there is a basic difference in the intraepithelial lymphocyte response in these two diseases.

Why the levels of intraepithelial lymphocytes become lower when cow's milk is removed from the diet, whether the child is milk sensitive or not, is unclear. It is possible that the hypoallergenic nature of cow's milk-free diets brings about the reduction, or that milk protein has a chemotactic effect on intraepithelial lymphocytes. Ferguson (1977) has suggested that intraepithelial lymphocytes may function by combining with antigen, removing it from the interepithelial spaces, thus preventing it from interreacting with the bodies own potentially harmful immune systems. If this is so, when the allergenic nature of the diet is reduced a lower number of intraepithelial lymphocytes might be expected. However, it would also be expected that when the mucosa is damaged, and presumably antigen entry is increased, then an increase in intraepithelial lymphocytes would also occur. This happens in coeliac disease (Lancaster-Smith et al., 1976; Mavromichalis et al., 1976), but in acute gastroenteritis and in post-enteritis enteropathy where severe mucosal damage occurs (Barnes and Townley, 1973; Gribbin et al., 1976) the level of intraepithelial lymphocytes is normal (Ferguson et al., 1976; Kilby and Walker-Smith, personal communication). As yet, this contradiction remains unexplained and the role of the intraepithelial lymphocyte obscure.

We are indebted to Mrs Faith Byron for the preparation of the histological sections and to Miss I. K. Haverly for secretarial work. We also thank the Queen Elizabeth Hospital for Children Research Appeal Trust for their financial support.

\section{References}

Barnes, G. L., and Townley, R. R. W. (1973). Duodenal mucosal damage in 31 infants with gastroenteritis. Archives of Disease in Childhood, 48, 343-349.

de Peyer, E., France, N. E., Phillips, A. D., and WalkerSmith, J. A. (1978). Quantitative evaluation of small intestinal morphology in childhood. Acta Paediatrica Belgica, 31, 173.

Ferguson, A. (1974). Lymphocytes in coeliac disease. In Coeliac Disease: Proceedings of the Second International Coeliac Symposium, pp. 265-276. Edited by W. T. J. M. Hekkens and A. S. Peña. Stenfert Kroese: Leyden.

Ferguson, A. (1977). Intraepithelial lymphocytes of the small intestine. Gut, 18, 921-937.

Ferguson, A., McClure, J. P., and Townley, R. R. W. (1976). Intraepithelial lymphocyte counts in small intestinal biopsies from children with diarrhoea. Acta Paediatrica Scandinavica, 65, 541-546.

Ferguson, A., and Murray, D. (1971). Quantitation of intraepithelial lymphocytes in human jejunum. Gut, 12, 988-994.

Gribbin, M., Walker-Smith, J. A., and Wood, C. (1976). Delayed recovery following acute gastroenteritis. Acta Paediatrica Belgica, 29, 167-176.

Kilby, A. (1976). Paediatric small intestinal biopsy capsule with two ports. Gut, 17, 158-159.

Lancaster-Smith, M., Packer, S., Kumar, P. J., and Harries, J. T. (1976). Cellular infiltrate of the jejunum after re-introduction of dietary gluten in children with treated coeliac disease. Journal of Clincial Pathology, 29, 587-591.

McNicholl, B., Egan-Mitchell, B., Stevens, F., Keane, R., Baker, S., McCarthy, C. F., and Fottrell, P. F. (1976). Mucosal recovery in treated childhood celiac disease (gluten sensitive enteropathy). Journal of Paediatrics, 89, 418-424.

Mavromichalis, J., Brueton, M. J., McNeish, A. S., and Anderson, C. M. (1976). Evaluation of the intraepithelial lymphocyte count in the jejunum in childhood enteropathies, Gut, 17, 600-603.

Walker-Smith, J. A., Harrison, M., Kilby, A., Phillips, A. D., and France, N. E. (1978). Cow's milk-sensitive enteropathy. Archives of Disease in Childhood, 53, 375-380. 